\title{
Cardiac Interventions in Symptomatic Patients $\geq 90$-Years-Old (Nonagenarians): A Single-Center Retrospective Analysis of Spectrum and Outcome
}

\author{
Philippe N Müller ${ }^{1}$, Christine H Attenhofer Jost, $M D^{1^{*}}$, Osmund Bertel, MD ${ }^{1}$, Barbara \\ Naegeli, $M D^{1}$, Edwin Straumann, $M D^{1}$, Pierre Levis, $M D^{1}$, Burkhardt Seifert ${ }^{1,2}$, Dominik \\ Maurer, $M D^{1}$, Christoph Scharf, $M D^{1}$, Olaf Franzen, $M D^{1}$ and Franz Wolfgang Amann, \\ $M D^{1}$
}

${ }^{1}$ Cardiovascular Center Zurich, Zurich, Switzerland

${ }^{2}$ Department of Biostatistics at Epidemiology, Cardiovascular Center Zurich, Zurich, Biostatistics and Prevention Institute, University of Zurich, Switzerland

*Corresponding author: Christine H Attenhofer Jost, MD, Cardiovascular Center Zurich, Klinik Im Park, Seestr. 220, 8027 Zürich, Switzerland, Tel: +41-44-209-20-20, Fax: +41-44-209-20-29

\begin{abstract}
Introduction: The number of very old patients with cardiac disease is increasing due to the longer life expectancy. There are few data on incidence and outcome of percutaneous cardiac procedures in patients $\geq 90$-years-old (nonagenarians).

Aim of the study: To retrospectively analyse the spectrum and outcome of percutaneous cardiac procedures in nonagenarians at our center.

Methods: The database at our center from 2005-2014 was searched for all percutaneous cardiac procedures, including coronary angiography with or without percutaneous coronary intervention $(\mathrm{PCl})$, transcatheter aortic valve replacement (TAVR), percutaneous mitral valve repair by MitraClip (PMVR), balloon valvuloplasty of the aortic valve (ABVP) and radiofrequency ablation (RFA). Age at procedure, clinical data, type and findings at procedure, in-hospital outcome, survival and predictors for survival were analyzed.

Results: Among 25,860 percutaneous cardiac procedures, $130(0.5 \%)$ were performed in 93 nonagenarians including 48 women (mean age $91.7 \pm 1.8$ years at first procedure). Procedures included 85 coronary angiographies (45 including $\mathrm{PCI}$ ), 25 TAVR, 11 ABVP, 6 PMVR (including one combined with TAVR), and 3 RFA. Overall survival after first procedure $(n=93)$ was $95 \%$ after 1 month, $78 \%$ after 1 year and $64 \%$ after 2 years. Left ventricular ejection fraction
\end{abstract}

(LVEF) $<40 \%$, history of heart failure, dyspnea NYHA III or IV, mitral valve insufficiency and history of atrial fibrillation were statistically significantly associated with worse estimated survival ( $p<0.05$, log-rank). These factors showed a strong collinearity in a multivariate survival analysis.

Conclusion: Percutaneous cardiac procedures in nonagenarians represent $0.5 \%$ of our procedures and have an acceptable survival rate considering the overall life expectancy in this age group. Further studies are required to delineate optimal patient selection in this age group for an acceptable ratio of procedural risk and benefit regarding survival and quality of life.

\section{Introduction}

The number of very old patients with cardiac disease has been increasing over recent years due to population growth and longer life expectancy [1]. In Switzerland, the estimated life expectancy for patients being 90-years-old (nonagenarians) in 2015 was is 4.11 years for men and 4.75 years for women [2]. In 2015, there was an estimate of more than 70,000 nonagenarians living in Switzerland, of which $72 \%$ were females [3]. According to the Federal Department for Statistics in Switzerland, the population of people over 90 years of age will increase to 140,000 and 215,000 in 2025 and 2035

Citation: Müller PN, Jost CHA, Bertel O, Naegeli B, Straumann E, et al. (2019) Cardiac Interventions in Symptomatic Patients $\geq 90$-Years-Old (Nonagenarians): A Single-Center Retrospective Analysis of Spectrum and Outcome. Int Arch Cardiovasc Dis 3:022. doi.org/10.23937/2643-3966/1710022 Accepted: August 26, 2019; Published: August 28, 2019

Copyright: (C) 2019 Müller PN, et al. This is an open-access article distributed under the terms of the Creative Commons Attribution License, which permits unrestricted use, distribution, and reproduction in any medium, provided the original author and source are credited. 
respectively [4]. The aging heart may be affected by coronary artery disease [5], valvular heart disease [6], diastolic dysfunction [7] and arrhythmias [8]. Therefore, management of these cardiovascular degenerative changes in the very old poses an increasing health problem and there are few data on optimal patient selection and on incidence and outcome of diagnostic and therapeutic cardiac procedures in the very old $[9,10]$. Many nonagenarians still enjoy a good quality of life, they and their relatives often demand an intervention to maintain this quality. Therefore, analysis of these data is important. Additionally, there are economic discussions how to quantify the benefit.

This study analyses the spectrum and outcome of percutaneous cardiac procedures in nonagenarians at our center including predictors of survival.

\section{Methods}

This retrospective study included all invasive diagnostic and/or therapeutic percutaneous cardiac procedures in patients 90 years of age or greater from January 2005 to December 2014 at our center. The procedures were coronary angiography with or without percutaneous coronary intervention $(\mathrm{PCl})$, transcatheter aortic valve replacement (TAVR), percutaneous mitral valve repair by MitraClip (PMVR), balloon valvuloplasty of the aortic valve (ABVP) and radiofrequency ablation (RFA). Patients with pacemaker implantation or cardiac surgery were not included. We analysed the baseline characteristics and cardiac findings prior to the procedure, the in-hospital outcome and survival where available. These data were assessed retrospectively from internal charts and reports from the referring physicians and/or other hospitals. This study was approved by the local ethics committee (KEK-ZH-Nr. 2015-0379).

\section{Definitions}

A procedure was considered elective or urgent by reported indication in the procedural report. BMI was considered low when $<20 \mathrm{~kg} / \mathrm{m}^{2}$. Significant weightloss was defined as reported weight-loss $\geq 10 \%$ of total body weight over the last 6 months. The living situation at the time of the procedure was assessed using the patients living address and/or medical reports, dividing into three groups: Own apartment, senior residency or nursing home. Pulmonary artery hypertension was defined as estimated or directly measured pulmonary mean artery pressure $>35 \mathrm{mmHg}$. Peri-procedural bleeding complications were considered significant if resulting in hemodynamic compromise, requiring blood transfusions or surgical intervention, or being located intracerebral (moderate or severe bleeding according to the Global Use of Strategies to Open Occluded Arteries definition, [11]).

\section{Indication for cardiac procedure}

All patients were referred either by their primary physician or their cardiologist to our center. Indication assessment and peri-procedural decision making were performed individually by our experienced interventional cardiologists and/or by the "Heart Team" where appropriate, always in consent with the patient and their families.

\section{Outcome and follow-up}

Follow-up data were assessed until May 2015, using the internal or external reported patient contacts in our clinic-database. For in-hospital outcome, the primary endpoint was all-cause-death. Secondary endpoints for in-hospital outcome where significant bleeding, stroke and other vascular complications. Regarding follow-up after hospital discharge, we chose all-cause-death as the only endpoint. A patient without reported patient contact after $1^{\text {st }}$ of February 2015 was considered as lost to follow-up. As some patients had two or more percutaneous cardiac procedures, we chose to analyse the outcome of the procedure per procedure (descriptive statistics only) as well as per patient (descriptive and comparative statistics). Data for calculating the expected survival of an age and sex matched Swiss population was acquired by online-resources of the Swiss Federal Statistical Office [12].

\section{Statistical analysis}

Continuous variables were described using mean \pm standard deviation (SD) or median and range. Categorical variables were presented as numbers and percentages. Estimated survival was assessed using the Kaplan-Meier method. Expected survival of an age and sex matched Swiss population was computed using the $\mathrm{R}$ package survival. Predictors for survival were compared using univariate (log-rank test) and multivariate (Cox-regression) survival analysis, considering a $p$ value of $<0.05$ as statistically significant.

\section{Results}

\section{Study population and spectrum of cardiac proce- dures}

There were 131 percutaneous cardiac procedures in 94 nonagenarians from 2005 to 2014 at our center, which represent $0.5 \%$ of a total of 25,860 percutaneous cardiac procedures conducted in the same time period. One patient withdrew consent leaving 130 procedures in 93 nonagenarians to be further analysed. From 2005 to $2009,43(0.37 \%$ of totally 11,747$)$ percutaneous cardiac procedures were performed in nonagenarians with an increase to $87(0.62 \%$ of totally 14,113$)$ procedures from 2010 to 2014. Table 1 shows the summary of the conducted procedures per year from 2005 to 2014. There were 45 coronary angiographies performed with $\mathrm{PCl}$ and 40 coronary angiographies without $\mathrm{PCl}$. Sixty-two coronary angiographies were elective, 23 were urgent. One patient had a TAVR and PMVR during the same procedural session, which was counted only once 
(as TAVR) for the total count, but included in both groups for respective survival analysis (hence the plus one in brackets for PMVR).

The indication for elective coronary angiography, TAVR, ABVP and PMVR was based on a reduction of quality of life by an underlying valvular pathology and/ or suspicion of coronary artery disease. The indications for the three RFA in our study population was symptomatic atrial flutter, atrial fibrillation respectively atrioventricular node re-entry tachycardia. The indication for urgent cardiac procedures was acute coronary syn- drome in coronary angiography and severe cardiac decompensation with severe aortic stenosis or severe mitral regurgitation in ABVP and PMVR. The indication was evaluated individually and in consent with the patient and their families.

\section{Baseline characteristics, cardiac and laboratory findings}

Baseline characteristics, cardiac and laboratory findings were assessed per procedure $(n=130)$ and per patient ( $n=93$, at first procedure) and are shown in Table 2. Mean age at time of procedure was 91.9 years.

Table 1: Number and spectrum of percutaneous cardiac procedures in nonagenarians per year from 2005 to 2014 at our center.

\begin{tabular}{|c|c|c|c|c|c|c|c|c|c|c|c|c|}
\hline & & 옹 & ஜ̊ & 오 & $\stackrel{\infty}{\stackrel{్}{N}}$ & ஓ & $\stackrel{\circ}{\circ}$ & $\underset{\check{D}}{\check{N}}$ & $\stackrel{\sim}{\check{D}}$ & $\stackrel{m}{\stackrel{\infty}{N}}$ & $\stackrel{+}{\grave{N}}$ & $\begin{array}{l}\bar{\pi} \\
\stackrel{5}{+}\end{array}$ \\
\hline \multirow{2}{*}{$\begin{array}{l}\text { Coronary } \\
\text { angiography }\end{array}$} & elective & 3 & 2 & 3 & 6 & 6 & 10 & 1 & 6 & 17 & 8 & 62 \\
\hline & urgent & 1 & 1 & 2 & 2 & 2 & 3 & - & 6 & 2 & 4 & 23 \\
\hline \multicolumn{2}{|l|}{ TAVR } & - & - & - & 3 & 3 & 1 & 2 & 3 & 9 & 4 & 25 \\
\hline \multirow[t]{2}{*}{ ABVP } & elective & - & - & 2 & 1 & 1 & 3 & - & - & - & - & 7 \\
\hline & urgent & - & - & - & 2 & 1 & - & - & 1 & - & - & 4 \\
\hline \multirow[t]{2}{*}{ PMVR } & elective & - & - & - & - & - & - & - & - & 1 & $2(+1)$ & $3(+1)$ \\
\hline & urgent & - & - & - & - & - & - & - & 1 & - & 2 & 3 \\
\hline \multicolumn{2}{|l|}{ RFA } & - & - & - & - & 2 & - & - & - & 1 & - & 3 \\
\hline \multicolumn{2}{|l|}{ All procedures } & 4 & 3 & 7 & 14 & 15 & 17 & 3 & 17 & 30 & $20(+1)$ & $130(+1)$ \\
\hline
\end{tabular}

ABVP: Aortic valve balloon valvuloplasty; RFA: Radiofrequency ablation; TAVR: Transcatheter aortic valve implantation; PMVR: Percutaneous mitral valve repair.

Table 2: Clinical characteristics, cardiac and laboratory findings per procedure $(n=130)$ and per patient $(n=93)$.

\begin{tabular}{|c|c|c|c|c|c|}
\hline & All procedures $(n=$ & All patients (at first & procedure, $\mathbf{n}=$ & & \\
\hline & & All patients $(n=93)$ & Males $(n=45)$ & Females $(n=48)$ & p-value \\
\hline Age, years & $91.9 \pm 2.0$ & $91.7 \pm 1.8$ & $91.8 \pm 1.7$ & $91.6 \pm 1.8$ & 0.48 \\
\hline & 91 (90 to 100$)$ & 91 (90 to 97 ) & 91 (90 to 97 ) & 91 (90 to 97 ) & \\
\hline Male gender & $66(51 \%)$ & $45(48 \%)$ & - & - & - \\
\hline 2 procedures $\geq 90$ years & - & $33(36 \%)$ & $19(42 \%)$ & $14(29 \%)$ & 0.20 \\
\hline 3 procedures $\geq 90$ years & - & $2(2 \%)$ & $1(2 \%)$ & $1(2 \%)$ & 1.0 \\
\hline $\mathrm{BMI}<20 \mathrm{~kg} / \mathrm{m}^{2}$ & $20(16 \%, n=128)$ & $15(17 \%, n=91)$ & $4(9 \%, n=44)$ & $11(23 \%, n=47)$ & 0.09 \\
\hline Living situation & & & & & \\
\hline - own apartment & 77 (59\%) & $58(62 \%)$ & $28(62 \%)$ & $30(63 \%)$ & 1.0 \\
\hline - senior residency & $53(41 \%)$ & $35(38 \%)$ & $17(38 \%)$ & $18(38 \%)$ & 1.0 \\
\hline - nursing home & 0 & 0 & 0 & 0 & 1.0 \\
\hline History of smoking & $11(8 \%, n=129)$ & $7(8 \%, n=92)$ & $5(11 \%)$ & $2(4 \%, n=47)$ & 0.14 \\
\hline Unintended weight loss & $3(2 \%)$ & $3(3 \%)$ & 0 & $3(6 \%)$ & 0.24 \\
\hline Arterial hypertension & $96(74 \%, n=130)$ & $69(75 \%, n=92)$ & $29(64 \%)$ & $40(85 \%, n=47)$ & 0.030 \\
\hline Obesity & $2(2 \%, n=128)$ & $2(2 \%, n=91)$ & $0(n=44)$ & $2(4 \%, n=47)$ & 0.50 \\
\hline Dyslipidemia & $19(15 \%, n=129)$ & $15(16 \%, n=92)$ & $7(16 \%)$ & $8(17 \%, n=47)$ & 1.0 \\
\hline Diabetes & $11(9 \%, n=129)$ & $8(9 \%, n=92)$ & $3(7 \%)$ & $5(11 \%, n=47)$ & 0.71 \\
\hline $\begin{array}{l}\text { Positive family history for } \\
\text { CAD }\end{array}$ & $5(4 \%, n=129)$ & $3(3 \%, n=92)$ & $2(4 \%)$ & $1(2 \%, n=47)$ & 0.61 \\
\hline Prior heart failure & $66(51 \%, n=129)$ & $45(49 \%, n=932)$ & $25(56 \%)$ & $20(43 \%, n=47)$ & 0.30 \\
\hline Prior stroke or TIA & $15(12 \%, n=129)$ & $11(12 \%, n=92)$ & $7(16 \%)$ & $4(9 \%, n=47)$ & 0.35 \\
\hline Prior myocardial infarction & $18(14 \%, n=129)$ & $13(14 \%, n=92)$ & $8(18 \%)$ & $5(11 \%, n=47)$ & 0.38 \\
\hline
\end{tabular}




\begin{tabular}{|l|l|l|l|l|l|}
\hline $\begin{array}{l}\text { Prior coronary } \\
\text { revascularisation }\end{array}$ & $43(33 \%, \mathrm{n}=129)$ & $25(27 \%, \mathrm{n}=92)$ & $16(36 \%)$ & $9(19 \%, \mathrm{n}=47)$ & 0.10 \\
\hline Cancer (non-metastatic) & $7(5 \%, \mathrm{n}=129)$ & $5(5 \%, \mathrm{n}=92)$ & $4(9 \%)$ & $1(2 \%, \mathrm{n}=47)$ & 0.20 \\
\hline COPD & $13(10 \%, \mathrm{n}=129)$ & $9(10 \%, \mathrm{n}=92)$ & $7(16 \%)$ & $2(4 \%, \mathrm{n}=47)$ & 0.087 \\
\hline NYHA functional class IV & $42(32 \%)$ & $28(30 \%)$ & $14(31 \%)$ & $14(29 \%)$ & 1.0 \\
\hline Angina pectoris & $54(42 \%)$ & $42(45 \%)$ & $20(44 \%)$ & $22(46 \%)$ & 1.0 \\
\hline Coronary artery disease & $100(77 \%)$ & $72(77 \%)$ & $38(84 \%)$ & $34(71 \%)$ & 0.14 \\
\hline $\begin{array}{l}\text { LVEF, } \% \\
\text { LVEF < } 50 \%\end{array}$ & $52 \pm 15$ & $53 \pm 16$ & $49 \pm 16$ & $56 \pm 15$ & 0.020 \\
\hline Severe aortic valve stenosis & $51(38 \%, \mathrm{n}=128)$ & $33(36 \%, \mathrm{n}=91)$ & $21(48 \%, \mathrm{n}=44)$ & $12(26 \%, \mathrm{n}=47)$ & 0.032 \\
\hline $\begin{array}{l}\text { Severe mitral valve } \\
\text { insufficiency }\end{array}$ & $11(9 \%, \mathrm{n}=128)$ & $8(9 \%, \mathrm{n}=91)$ & $4(9 \%, \mathrm{n}=44)$ & $4(9 \%, \mathrm{n}=47)$ & 0.96 \\
\hline Atrial fibrillation ever & $38(29 \%)$ & $28(30 \%, \mathrm{n}=92)$ & $13(29 \%)$ & $15(32 \%, \mathrm{n}=47)$ & 0.67 \\
\hline $\begin{array}{l}\text { Pulmonary artery } \\
\text { hypertension }\end{array}$ & $85(73 \%, \mathrm{n}=116)$ & $56(69 \%, \mathrm{n}=81)$ & $27(69 \%, \mathrm{n}=39)$ & $29(69 \%, \mathrm{n}=42)$ & 1.0 \\
\hline GFR < $60 \mathrm{ml} /$ min & $87(68 \%, \mathrm{n}=128)$ & $66(72 \%, \mathrm{n}=92)$ & $33(73 \%)$ & $33(70 \%, \mathrm{n}=47)$ & 0.82 \\
\hline GFR < 30 ml/min & $11(9 \%, \mathrm{n}=128)$ & $8(9 \%, \mathrm{n}=92)$ & $5(11 \%)$ & $3(6 \%, \mathrm{n}=47)$ & 0.48 \\
\hline Hb < $110 \mathrm{~g} / \mathrm{L}$ & $33(26 \%, \mathrm{n}=129)$ & $20(22 \%)$ & $7(16 \%)$ & $13(27 \%)$ \\
\hline
\end{tabular}

BMI: Body mass index; CABG: Coronary artery bypass grafting; CAD: Coronary artery disease; COPD: Chronic obstructive pulmonary disease; GFR: Glomerular filtration rate; Hb: Haemoglobin; LVEF: Left ventricular ejection fraction; N: Number of patients; NYHA: New York Heart association; PCI: Percutaneous coronary intervention; TIA: Transient ischemic attack;

Continuous values are written as mean \pm standard deviation and/or median with range.

Table 3: Peri-procedural characteristics, all procedures $(n=130)$.

\begin{tabular}{|c|c|c|c|c|c|c|}
\hline & $\begin{array}{l}\text { All procedures } \\
(n=130)\end{array}$ & $\begin{array}{l}\text { Coronary } \\
\text { angiography } \\
(n=85)\end{array}$ & $\begin{array}{l}\text { TAVR } \\
(n=25)\end{array}$ & $\begin{array}{l}\text { ABVP } \\
(n=11)\end{array}$ & $\begin{array}{l}\text { PMVR } \\
(n=6+1)\end{array}$ & $\begin{array}{l}\text { RFA } \\
(n=3)\end{array}$ \\
\hline Mean length of hospitalisation (d) & $6.5 \pm 7.6$ & $4.0 \pm 5.1$ & $11.7 \pm 10.1$ & $8.9 \pm 7.4$ & $22.6 \pm 13.6$ & $2.0 \pm 1.0$ \\
\hline Median length of hospitalisation (d) & $2.5(1,50)$ & $2(1$ to 25$)$ & $8(1$ to 50$)$ & $7(2$ to 22$)$ & 21 (8 to 50$)$ & 2 (1 to 3$)$ \\
\hline Procedure related death & $1(0.7 \%)$ & 0 & $1(4 \%)$ & 0 & 0 & 0 \\
\hline In-hospital death & $6(5 \%)$ & $3(4 \%)$ & $2(8 \%)$ & $1(9 \%)$ & 0 & 0 \\
\hline Femoral hematoma & $2(2 \%)$ & $1(1 \%)$ & 0 & 0 & $1(14 \%)$ & 0 \\
\hline Coronary artery perforation & $2(2 \%)$ & $2(2 \%)$ & 0 & 0 & 0 & 0 \\
\hline Other bleeding complications & $2(2 \%)$ & 0 & $1(4 \%)$ & $1(9 \%)$ & 0 & 0 \\
\hline Stroke during hospitalisation & $2(2 \%)$ & $1(1 \%)$ & $1(4 \%)$ & 0 & 0 & 0 \\
\hline
\end{tabular}

ABVP: Aortic balloon valvuloplasty; d: Days; n: Number of patients; PMVR: Percutaneous mitral valve repair; RFA: Radiofrequency ablation; TAVR: Transcatheter aortic valve replacement.

Continuous values are written as mean \pm standard deviation and/or median with range.

Approximately half of all procedures (51\%) were performed in male patients. No procedures were performed in patients living in a nursing home. Thirty-three patients had two procedures at the age of $\geq 90$ years. There were two patients who underwent 3 procedures: One patient had diagnostic coronary angiography and two consecutive ABVP, the other one had diagnostic coronary angiography with two consecutive sessions of $\mathrm{PCl}$. Baseline characteristics at first procedure showed very similar results between genders, except a higher frequency of arterial hypertension and higher mean left ventricular ejection fraction in women.

\section{Peri-procedural characteristics}

Median length of hospitalisation was 2.5 days, with a range of one to 50 days. The patient with 50 days of hospitalisation underwent combined TAVR and PVMR and had a prolonged recovery time without stroke or another vascular complication, but with prolonged mobilisation. There was one single procedure related death during TAVR, where the device repeatedly embolized into the left ventricle with decision against surgical intervention. Overall, in-hospital mortality was $5 \%$ and was mostly caused by progression of pre-procedural cardiac decompensation despite successful procedure and/or non-procedure related complications such as pneumonia. Only one case of gastrointestinal bleeding after AVBP contributed to in-hospital death. There were two cases of coronary artery perforation, of which one required pericardiocentesis. Femoral bleeding requiring 
surgical intervention occurred in one case of coronary angiography and PMVR. The other two bleeding complications requiring blood transfusion included the gastrointestinal bleeding mentioned above and one case of unspecific peri-procedural blood loss during TAVR. All peri-procedural characteristics are listed in Table 3.

\section{Survival after first procedure}

We performed further comparison regarding the estimated survival of our 93 patients after their first

Table 4: Estimated survival after first procedure $(n=93)$.

\begin{tabular}{|c|c|c|c|c|c|c|c|}
\hline & & 1 month & 6 months & 1 year & 2 years & 5 years & $\begin{array}{l}\text { Follow-up } \\
\text { (months) }\end{array}$ \\
\hline First procedure $(n=93)$ & $\begin{array}{l}\text { Survival } \\
\text { Lost to follow up }\end{array}$ & $\begin{array}{l}95 \%(88) \\
-\end{array}$ & $\begin{array}{l}85 \%(77) \\
-\end{array}$ & $\begin{array}{l}78 \%(66) \\
1\end{array}$ & $\begin{array}{l}64 \%(38) \\
3\end{array}$ & $\begin{array}{l}39 \%(8) \\
9\end{array}$ & $\begin{array}{l}26.9 \pm 24.5 \\
18.5(0 \text { to } 108.2)\end{array}$ \\
\hline $\begin{array}{l}\text { First Coronary Angiography } \\
(n=74)\end{array}$ & $\begin{array}{l}\text { Survival } \\
\text { Lost to follow up }\end{array}$ & $\begin{array}{l}93 \%(69) \\
-\end{array}$ & $\begin{array}{l}84 \%(61) \\
-\end{array}$ & $\begin{array}{l}78 \%(52) \\
1\end{array}$ & $\begin{array}{l}62 \%(30) \\
3\end{array}$ & $\begin{array}{l}37 \%(7) \\
6\end{array}$ & $\begin{array}{l}26.9 \pm 25.2 \\
18.0(0 \text { to } 108.2)\end{array}$ \\
\hline - With $\mathrm{PCl}(\mathrm{n}=36)$ & $\begin{array}{l}\text { Survival } \\
\text { Lost to follow up }\end{array}$ & $\begin{array}{l}94 \%(34) \\
-\end{array}$ & $\begin{array}{l}83 \%(30) \\
-\end{array}$ & $\begin{array}{l}78 \%(25) \\
-\end{array}$ & $\begin{array}{l}63 \%(13) \\
2\end{array}$ & $\begin{array}{l}58 \%(5) \\
3\end{array}$ & $\begin{array}{l}29.7 \pm 29.3 \\
16.8(0 \text { to } 108.2)\end{array}$ \\
\hline -Without $\mathrm{PCI}(\mathrm{n}=38)$ & $\begin{array}{l}\text { Survival } \\
\text { Lost to follow up }\end{array}$ & $\begin{array}{l}92 \%(35) \\
-\end{array}$ & $\begin{array}{l}84 \%(31) \\
-\end{array}$ & $\begin{array}{l}79 \%(27) \\
1\end{array}$ & $\begin{array}{l}62 \%(17) \\
1\end{array}$ & $\begin{array}{l}19 \%(2) \\
3\end{array}$ & $\begin{array}{l}24.3 \pm 20.6 \\
20.1(0.3 \text { to } 99.7)\end{array}$ \\
\hline First TAVR $(n=25)$ & $\begin{array}{l}\text { Survival } \\
\text { Lost to follow up }\end{array}$ & $\begin{array}{l}92 \%(23) \\
-\end{array}$ & $\begin{array}{l}84 \%(20) \\
-\end{array}$ & $80 \%(18)$ & $\begin{array}{l}73 \%(11) \\
-\end{array}$ & $\begin{array}{l}65 \%(2) \\
3\end{array}$ & $\begin{array}{l}24.8 \pm 22.3 \\
19.9(0 \text { to } 78.5)\end{array}$ \\
\hline First AVBP $(n=10)$ & $\begin{array}{l}\text { Survival } \\
\text { Lost to follow up }\end{array}$ & $\begin{array}{l}100 \%(10) \\
-\end{array}$ & $\begin{array}{l}90 \%(9) \\
-\end{array}$ & $\begin{array}{l}80 \%(8) \\
-\end{array}$ & $\begin{array}{l}70 \%(7) \\
-\end{array}$ & $\begin{array}{l}30 \%(1) \\
1\end{array}$ & $\begin{array}{l}36.7 \pm 24.3 \\
32.6 \text { (4.7 to } 84.3)\end{array}$ \\
\hline First MitraClip $(n=6+1)$ & $\begin{array}{l}\text { Survival } \\
\text { Lost to follow up }\end{array}$ & $100 \%(6)$ & $83 \%(4)$ & $50 \%(2)$ & $\begin{array}{l}33 \%(1) \\
-\end{array}$ & - & $\begin{array}{l}12.6 \pm 11.6 \\
8.7(3.3 \text { to } 37.0)\end{array}$ \\
\hline
\end{tabular}

All survival rates are shown with patients at risk in brackets.

PCl: Percutaneous coronary intervention; RFA: Radiofrequency ablation; TAVR: Transcatheter aortic valve replacement;

Estimated Survival is written with patients at risk.

Continuous values are written as mean \pm standard deviation and/or median with range.

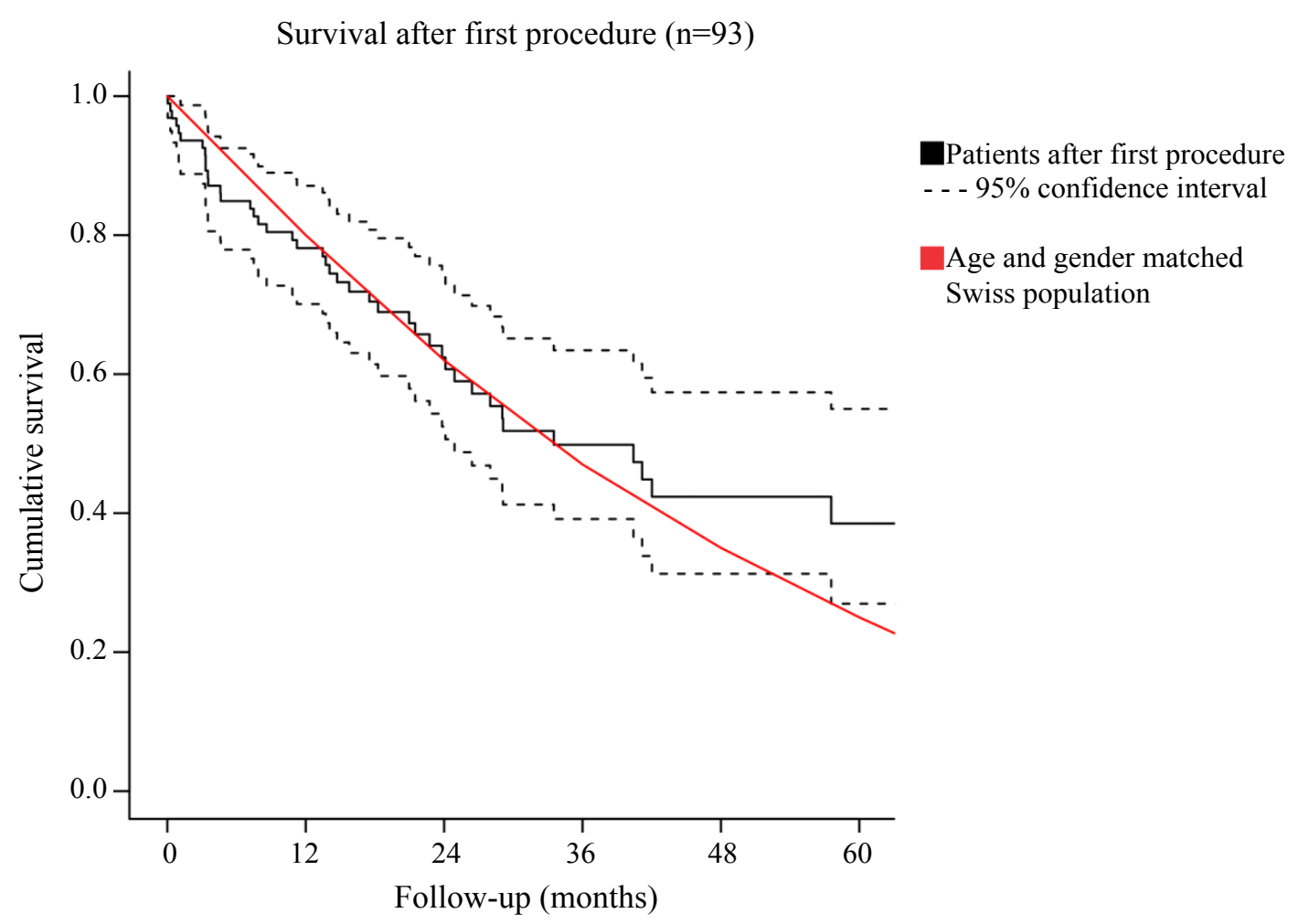

Figure 1: Estimated survival after first procedure $(n=93)$ with $95 \%$ confidence interval and mean survival of an age and gender matched Swiss population.

$\mathrm{n}=$ number of patients. 
percutaneous cardiac procedure at age $\geq 90$ years. Survival rates after first procedure in general and after first specific procedure are shown in Table 4. Survival after the first procedure was 95\% after 1 month, 78\% after 1 year and 64\% after 2 years. Mean survival of an age and gender matched Swiss population was $80 \%$ at 1 year and $62 \%$ at 2 years. The Kaplan-Meier curve of the survival after first procedure as well as the mean survival of an age and gender matched Swiss population are shown in Figure 1.

Survival after first coronary angiography (74 patients) was practically identical to the overall survival, being the biggest subgroup. There was no statistically significant difference in survival after first coronary angiography with $\mathrm{PCl}(\mathrm{n}=36)$ or without $\mathrm{PCl}(\mathrm{n}=38, \mathrm{p}=$ 0.19 , log-rank). There was also no statistically significant difference in survival after urgent vs. elective coronary angiographies in general ( $p=0.6$, log-rank) or within the subgroup with $\mathrm{PCl}(\mathrm{n}=36, \mathrm{p}=0.5$, log-rank), which is shown in the supplemental Table S1.

The Kaplan-Meier curves of the estimated survival after first coronary angiography and TAVR as well as the mean survival of an age and gender matched Swiss population are shown in supplemental Figure S1 and Figure S2.

\section{Predictors of lower estimated survival rate}

In a univariate survival analysis, the following factors were associated with a lower survival rate after first procedure ( $n=93,46$ deaths): history of heart failure ( $p=0.02$, log-rank), NYHA functional class III or IV ( $p=$ 0.045, log-rank), NYHA functional class IV ( $p=0.016$, log-rank), LVEF $<40 \%$ ( $p=0.01$, log-rank), mild to severe mitral valve insufficiency ( $p=0.38$, log-rank) and history of atrial fibrillation ( $p=0.038$, log-rank). None of these six factors remained statistical significant when adjusted for each other in a multivariate survival analysis. This underlines collinearity between these factors.

Regarding survival after first coronary angiography ( $n=74,39$ deaths), univariate survival analysis showed similar factors as associated with a lower survival rate: History of heart failure ( $p=0.006$, log-rank), NYHA functional class IV ( $p=0.006$, log-rank), peripheral edema ( $p=0.023$, log-rank), LVEF $<50 \%$ ( $p=0.01$, logrank), LVEF $<40 \%$ ( $p<0.001$, log-rank) and history of atrial fibrillation ( $p=0.016$, log-rank). None of these six factors remained statistical significant when adjusted for each other in a multivariate survival analysis. This again underlines collinearity between these factors.

No specific factor was significantly predictive of survival after TAVR. We did not perform any further survival analysis in the remaining treatment groups ABVP, PMVR and RFA due to their small patient numbers.

\section{Discussion}

Our results show that percutaneous cardiac procedures in nonagenarians are rare, however increasing representing $0.5 \%$ in our procedures. Most common procedures are coronary angiographies, PCI and TAVR. Two-year survival in our cohort was $64 \%$ and was negatively impacted by a decreased left ventricular ejection fraction, heart failure, mitral valve insufficiency and history of atrial fibrillation.

\section{Spectrum of cardiac procedures}

Our study showed an increasing number of percutaneous cardiac procedures performed in nonagenarians over time at our center. Most commonly performed procedures in this age group include coronary angiography and TAVR. There are only few studies about cardiac procedures in nonagenarians. Most of them analyse the outcome after $\mathrm{PCl}$ [13-21]. The number of nonagenarians undergoing TAVR was also comparable to previous studies [22,23]. The number of patients receiving ABVP, PMVR or RFA was small in our study.

\section{Pre-procedural findings}

All patients seemed to have a good quality of life before they were limited by progressive heart disease. The frequency and severity of frailty in our study population remains unclear since our retrospective analysis lacks data for an adequate evaluation. However, the fact that there were no patients living in nursing homes excluded severe frailty in our study population. We interprete these findings as result of patient selection. Except arterial hypertension, cardiovascular risk factors were rare in our study population. This may be due to natural selection.

\section{Peri-procedural complications}

The length of hospitalisation regarding procedures for valvular heart diseases in our study population where considerably longer than usually observed in younger age groups. The rate of peri-procedural complications is comparable to other studies that analysed peri-procedural complications in nonagenarians $[13-15,17,18]$, except the rate of coronary artery perforation. The rate of coronary artery perforation in our study population is high, compared to the literature where these rates range from $0.27 \%$ to $0.84 \%$ [24]. However, the reported mean age of the investigated patients ranges between 60-71 years, and older age is commonly considered as a risk factor [24]. In contrast, only one case of pericardial tamponade $(<1 \%)$ was reported in one study [14]. The rate of peri-procedural complications during TAVR was comparable to the results of Noble [23]. The rate of peri-procedural complications of the other procedural groups is not reliable due to their small patient numbers.

\section{Outcome after procedure and predictors for worse survival}

Compared to an age and gender matched Swiss population, survival after first percutaneous cardiac proce- 
dure in all analysed groups was similar. Survival-rate in our study population after urgent and elective coronary angiography seems to be comparable to previous study results [13,16-21]. However, the 1-month mortality of $5 \%$ after first procedure shows potential for better patient selection. The selection process whether (or not) to perform percutaneous cardiac procedures in our study population can not be assessed by our retrospective non-controlled study design.

It seems plausible that there is a strong collinearity between the 6 risk factors history of heart failure, NYHA functional class III or IV, LVEF $<40 \%$, mild to severe mitral valve insufficiency and history of atrial fibrillation. However, the reliability of a multivariate survival analysis adjusting for 6 factors with a total of 46 deaths remains unclear. Similarly, the reliability of a multivariate survival analysis in the subpopulation after first coronary angiography is also unclear. Amazingly, renal impairment was not associated with a worse survival in our study population.

The practical consequence for patient selection regarding the risk factors mentioned above should be further evaluated by also assessing post-procedural symptom relief, which was not possible in our retrospective study.

The low amount of elective percutaneous cardiac procedures in the literature in this age group can be interpreted as result of overall low patient numbers, which are possibly further lowered by restrictive patient selection since there is yet little evidence about risk and benefit. The resulting number of nonagenarians not getting an appropriate interventional therapy remains unclear. We think that our retrospective single center study can not answer the important question about the individual benefit, but shows an acceptable estimated survival after percutaneous cardiac procedure in this age group. In this age group, improvement of survival is not the main focus but better quality of life. Regarding the yet small number of nonagenarians undergoing cardiac procedures, multi-center and prospective studies are required to get better knowledge about factors concerning risks and benefits in this age group, allowing general recommendations for these patients.

\section{Study Limitations}

This was a single-center, retrospective study about a population being referred for percutaneous cardiac procedures. Therefore, there is certainly a significant referral and selection bias. Due to the retrospective design, data acquisition was limited, e.g. there was no prospective use of a frailty score. Considering the small number of patients and events, the reliability of a multivariate survival analysis is limited.

\section{Conclusion}

Nonagenarians undergoing elective and urgent per- cutaneous cardiac procedures at our center showed an acceptable survival considering the overall life expectancy in this age group. Length of hospitalisation for procedures regarding valvular heart disease are considerably longer than usually observed in younger age groups. In our study population, predictors of worse estimated survival after percutaneous cardiac procedure are history of heart failure, NYHA functional class III or IV, LVEF $<40 \%$, mild to severe mitral valve insufficiency and history of atrial fibrillation. Further studies in this age group are required to delineate optimal patient selection for an acceptable ratio of procedural risk and benefit regarding survival and quality of life.

\section{Statement on Funding Sources and Conflicts of Interest}

This research was funded by the HerzGefässStiftung but otherwise received no specific grant from any funding agency in the public, commercial, or not-for-profit sectors. Two co-authors declare a potential conflict of interest: Christoph Scharf MD is stockholder of Acutus Medical Inc. and Olaf Franzen MD is a consultant of Edwards.

\section{Statement of Equal Authors' Contribution}

All persons who meet authorship criteria are listed as authors, and all authors certify that they have participated sufficiently in the work to take public responsibility for the content.

\section{References}

1. Roth GA, Forouzanfar $M H$, Moran $A E$, Barber R, Nguyen $G$, et al. (2015) Demographic and epidemiologic drivers of global cardiovascular mortality. N Engl J Med 372: 13331341.

2. (2018) Periodensterbetafeln für die Schweiz (1900-2150) nach Jahr, Geschlecht und Alter. Bundesamt für Statistik BFS.

3. (2018) Ständige und nichtständige Wohnbevölkerung nach Jahr, Bevölkerungstyp, Staatsangehörigkeit (Kategorie), Geschlecht und Alter. Bundesamt für Statistik BFS.

4. (2018) Szenarien zur Bevölkerungsentwicklung der Schweiz ab 2015 - Bevölkerung und Bewegungen nach Szenario-Variante, Staatsangehörigkeit, Geschlecht, Alter, Jahr und Variable. Bundesamt für Statistik.

5. Thompson RC, Allam AH, Lombardi GP, Wann LS, Sutherland ML, et al. (2013) Atherosclerosis across 4000 years of human history: The Horus study of four ancient populations. Lancet 381: 1211-1222.

6. Sahasakul Y, Edwards WD, Naessens JM, Tajik AJ (1988) Age-related changes in aortic and mitral valve thickness: Implications for two-dimensional echocardiography based on an autopsy study of 200 normal human hearts. Am J Cardiol 62: 424-430.

7. Redfield MM, Jacobsen SJ, Borlaug BA, Rodeheffer RJ, Kass DA (2005) Age- and gender-related ventricularvascular stiffening: A community-based study. Circulation 112: 2254-2262.

8. Weirich J (2017) Remodeling of the aging heart: Sinus node 
dysfunction and atrial fibrillation. Herzschrittmacherther Elektrophysiol 28: 29-38.

9. Tsukui H, Yamazaki K (2014) Contemporary strategy for aortic valve stenosis in octogenarians. Surg Today 44: 992 1003.

10. Florath I, Albert A, Boening A, Ennker IC, Ennker J (2010) Aortic valve replacement in octogenarians: Identification of high-risk patients. Eur J Cardiothorac Surg 37: 1304-1310.

11. GUSTO Investigators (1993) An international randomized trial comparing four thrombolytic strategies for acute myocardial infarction. N Engl J Med 329: 673-682.

12. (2018) Todesfälle nach Geschlecht, Alter, Staatsangehörigkeit, Zivilstand und Jahr. Bundesamt für Statistik.

13. Appleby CE, Ivanov J, Mackie K, Džavík V, Overgaard CB (2011) In-hospital outcomes of very elderly patients (85 years and older) undergoing percutaneous coronary intervention. Cathet Cardiovasc Interve 77: 634-641.

14. Tegn N, Abdelnoor M, Aaberge L, Endresen K, Smith $P$, et al. (2016) Invasive versus conservative strategy in patients aged 80 years or older with non-ST-elevation myocardial infarction or unstable angina pectoris (After Eighty study): An open-label randomised controlled trial. Lancet 387 : 1057-1065.

15. Shah P, Najafi AH, Panza JA, Cooper HA (2009) Outcomes and quality of life in patients $\geq 85$ years of age with STelevation myocardial infarction. Am J Cardiol 103: 170-174.

16. Antonsen L, Jensen LO, Terkelsen CJ, Tilsted HH, Junker A, et al. (2013) Outcomes after primary percutaneous coronary intervention in octogenarians and nonagenarians with ST-segment elevation myocardial infarction: From the Western Denmark heart registry. Catheter Cardiovasc Interv 81: 912-919.
17. Danzi GB, Centola M, Pomidossi GA, Consonni D, De Matteis S, et al. (2010) Usefulness of primary angioplasty in nonagenarians with acute myocardial infarction. Am J Cardiol 106: 770-773.

18. Valente S, Lazzeri C, Salvadori C, Chiostri M, Giglioli C, et al. (2008) Effectiveness and safety of routine primary angioplasty in patients aged $>$ or $=85$ years with acute myocardial infarction. Circ J 72: 67-70.

19. Moreno R, Salazar A, Bañuelos C, Hernández R, Alfonso $F$, et al. (2004) Effectiveness of percutaneous coronary interventions in nonagenarians. Am J Cardiol 94: 10581060.

20. Teplitsky I, Assali A, Lev E, Brosh D, Vaknin-Assa H, et al. (2007) Results of percutaneous coronary interventions in patients $>$ or $=90$ years of age. Catheter Cardiovasc Interv 70: $937-943$

21. Lee MS, Zimmer R, Pessegueiro A, Jurewitz D, Tobis $J$ (2008) Outcomes of nonagenarians who undergo percutaneous coronary intervention with drug-eluting stents. Catheter Cardiovasc Interv 71: 526-530.

22. Pascual I, Muñoz-García AJ, López-Otero $D$, Avanzas $P$, Jimenez-Navarro MF, et al. (2015) Transcatheter aortic valve implantation in very elderly patients: Immediate results and medium term follow-up. J Geriatr Cardiol 12: 340-345.

23. Noble S, Frangos E, Samaras N, Ellenberger C, Frangos C, et al. (2013) Transcatheter aortic valve implantation in nonagenarians: Effective and safe. Eur J Intern Med 24: 750-755.

24. Shimony A, Joseph L, Mottillo S, Eisenberg MJ (2011) Coronary artery perforation during percutaneous coronary intervention: A systematic review and meta-analysis. Can J Cardiol 27: 843-850. 
Table S1: Estimated survival after first coronary angiography $(n=74)$ and after first coronary angiography with PCI $(n=41)$.

\begin{tabular}{|c|c|c|c|c|c|c|c|c|}
\hline & & 1 month & $\begin{array}{l}6 \\
\text { months }\end{array}$ & 1 year & 2 years & 5 years & $\begin{array}{l}\text { Follow-up } \\
\text { (months) }\end{array}$ & $\begin{array}{l}\text { p-value } \\
\text { (log-rank) }\end{array}$ \\
\hline $\begin{array}{l}\text { First Coronary } \\
\text { Angiography }(n=74)\end{array}$ & $\begin{array}{l}\text { Survival } \\
\text { Lost to follow up }\end{array}$ & $\begin{array}{l}93 \%(69) \\
-\end{array}$ & $\begin{array}{l}84 \%(61) \\
-\end{array}$ & $\begin{array}{l}78 \%(52) \\
1\end{array}$ & $\begin{array}{l}62 \%(31) \\
3\end{array}$ & $\begin{array}{l}37 \%(7) \\
6\end{array}$ & $\begin{array}{l}26.9 \pm 25.2 \\
18.0(0 \text { to } 108.2)\end{array}$ & \\
\hline - elective $(n=54)$ & $\begin{array}{l}\text { Survival } \\
\text { Lost to follow up }\end{array}$ & $\begin{array}{l}94 \%(51) \\
-\end{array}$ & $\begin{array}{l}87 \%(46) \\
-\end{array}$ & $81 \%(40)$ & $\begin{array}{l}67 \%(24) \\
1\end{array}$ & $\begin{array}{l}37 \%(6) \\
4\end{array}$ & $\begin{array}{l}29.0 \pm 25.5 \\
19.8(0 \text { to } 99.7)\end{array}$ & 0.59 \\
\hline - urgent $(n=20)$ & $\begin{array}{l}\text { Survival } \\
\text { Lost to follow up }\end{array}$ & $\begin{array}{l}90 \%(18) \\
-\end{array}$ & $\begin{array}{l}75 \%(15) \\
-\end{array}$ & $\begin{array}{l}70 \%(12) \\
1\end{array}$ & $\begin{array}{l}49 \%(6) \\
2\end{array}$ & $\begin{array}{l}41 \%(1) \\
2\end{array}$ & $\begin{array}{l}21.3 \pm 24.0 \\
14.6(0 \text { to } 108.2)\end{array}$ & \\
\hline $\begin{array}{l}\text { First Coronary } \\
\text { Angiography with } \\
\mathrm{PCl}(\mathrm{n}=36)\end{array}$ & $\begin{array}{l}\text { Survival } \\
\text { Lost to follow up }\end{array}$ & $\begin{array}{l}94 \%(34) \\
-\end{array}$ & $\begin{array}{l}83 \%(30) \\
-\end{array}$ & $\begin{array}{l}78 \%(25) \\
-\end{array}$ & $\begin{array}{l}63 \%(13) \\
2\end{array}$ & $\begin{array}{l}58 \%(5) \\
3\end{array}$ & $\begin{array}{l}29.7 \pm 29.3 \\
16.8(0 \text { to } 108.2)\end{array}$ & \\
\hline - elective $(n=21)$ & $\begin{array}{l}\text { Survival } \\
\text { Lost to follow up }\end{array}$ & $\begin{array}{l}100 \%(21) \\
-\end{array}$ & $\begin{array}{l}91 \%(19) \\
-\end{array}$ & $\begin{array}{l}86 \%(16) \\
-\end{array}$ & $\begin{array}{l}72 \%(9) \\
1\end{array}$ & $\begin{array}{l}64 \%(4) \\
2\end{array}$ & $\begin{array}{l}35.3 \pm 30.1 \\
21.3(1.2 \text { to } 95.2)\end{array}$ & 0.48 \\
\hline - urgent $(n=15)$ & $\begin{array}{l}\text { Survival } \\
\text { Lost to follow up }\end{array}$ & $87 \%(13)$ & $\begin{array}{l}73 \%(11) \\
-\end{array}$ & $66 \%(9)$ & $\begin{array}{l}50 \%(4) \\
1\end{array}$ & $\begin{array}{l}50 \%(1) \\
1\end{array}$ & $\begin{array}{l}21.9 \pm 27.2 \\
14.3(0 \text { to } 108.2)\end{array}$ & \\
\hline
\end{tabular}

All survival rates are shown with patients at risk in brackets.

$\mathrm{n}=$ Number of patients; $\mathrm{PCl}$ : Percutaneous coronary intervention.

Estimated Survival is written with patients at risk.

Continuous values are written as mean \pm standard deviation and/or median with range.

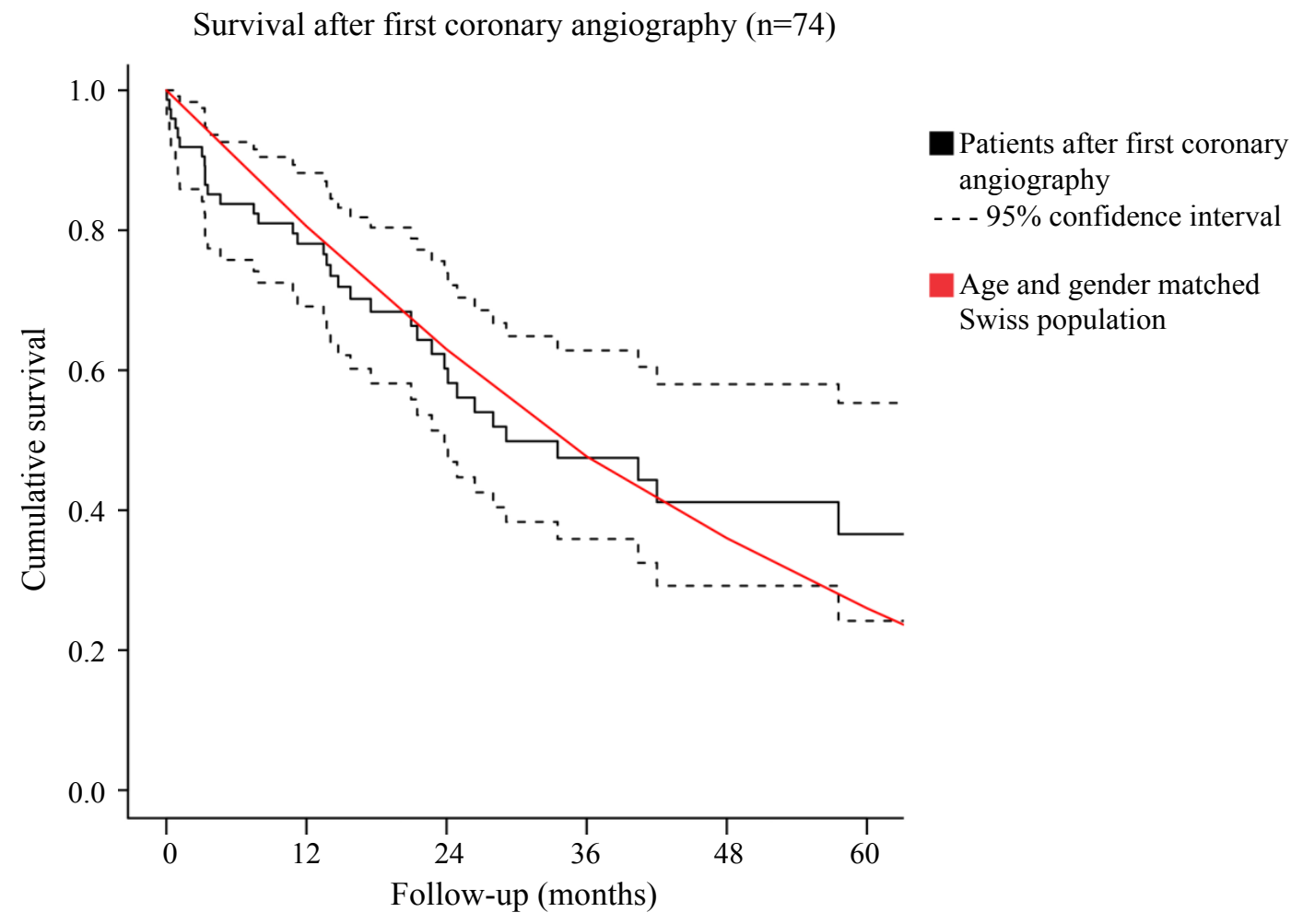

Figure S1: Estimated survival after first coronary angiography $(n=74)$ with $95 \%$ confidence interval and mean survival of an age and gender matched Swiss population.

$\mathrm{n}=$ Number of patients. 
Survival after first TAVR $(\mathrm{n}=25)$

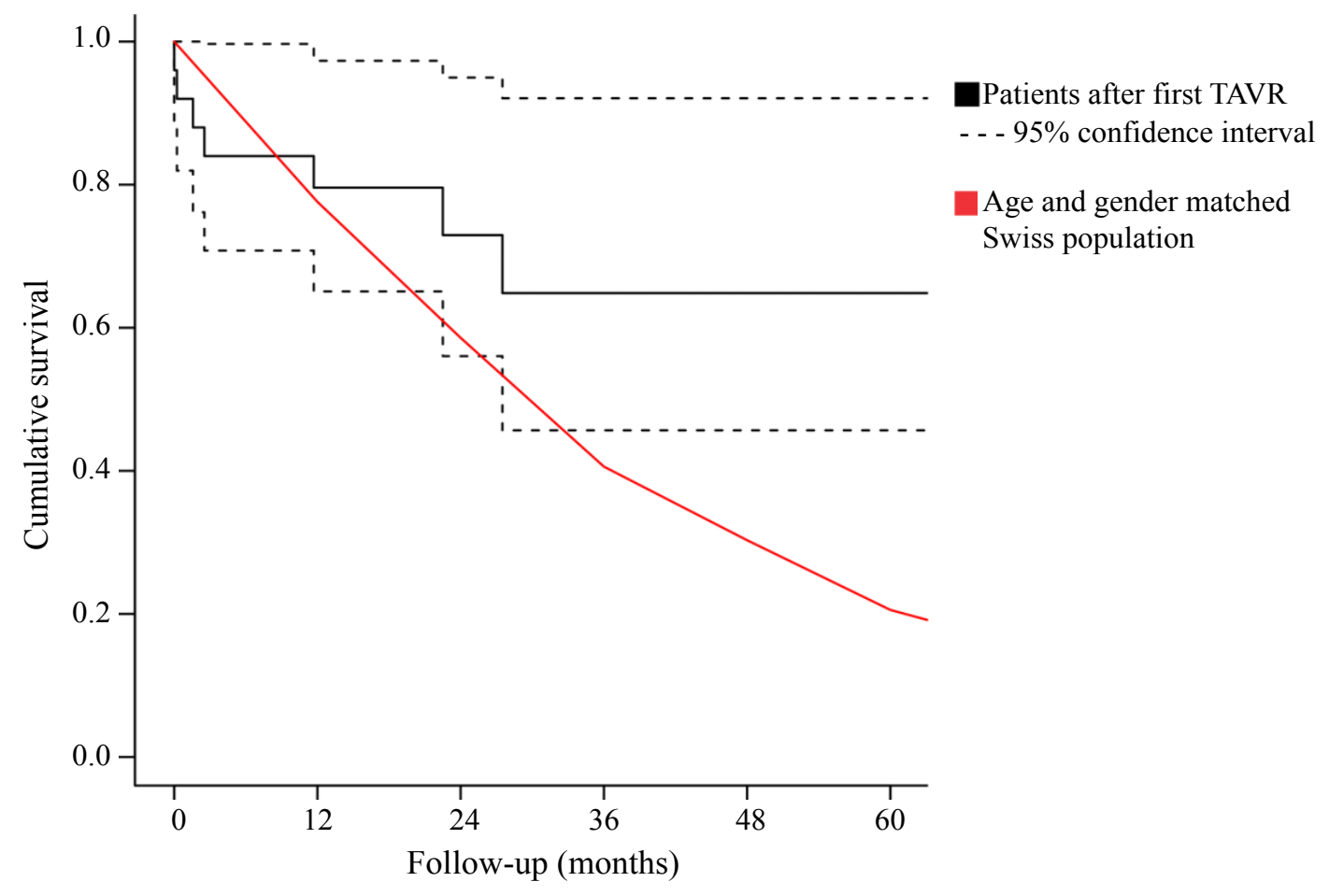

Figure S2: Estimated survival after first TAVR $(n=25)$ with 95\% confidence interval and mean survival of an age and gender matched Swiss population.

$\mathrm{n}=$ Number of patients; TAVR: Transcatheter aortic valve replacement. 